\title{
Special feature: evolutionary approaches in theory and policy to the diversity of money
}

\section{Makoto Nishibe $^{1}$}

Published online: 20 November 2018

(C) Japan Association for Evolutionary Economics 2018

EU's common currency, Euro, emerged in 2002 and expanded for a while, but declined because of sovereign debt crises in 2010 . We observe since then that diversity of money has not only spread all over the world but intensified in kind.

Only in the past few years, cryptocurrencies such as Bitcoin and other Altcoins/ tokens have rapidly become worldwide, expanded its scale, and increased its number. However, we have witnessed in the bubble burst of cryptocurrencies early this year that they have become quite volatile, speculative financial instruments to the extent that they can no longer be called 'currency' or 'money' to facilitate steady transactions. But, various social or community-oriented digital coins for promoting local consumption and social investments in the same spirit of community currencies have already been implemented or are currently planned not only in Japan but also in the world.

It is also frequently said that we are currently approaching a cashless economy where electronic representations of money replace traditional cash such as coin or bank note and the transaction can be done through transfer of digital information. Sweden is regarded as the best model of cashless economy. In East Asia, Korea and China are well-known as highly cashless economies, though Japan is notorious for being quite behind in this respect. Such a cashless economy must generate different kinds of digital representations of national currencies as well as non-national currencies.

Such non-national currencies as local currencies, community currencies, cryptocurrencies and local cryptocurrencies are thus expanding in terms of volume and kind. These are the observable facts that cannot be denied by anybody. But, we are not satisfied with only describing such ongoing facts. We should also explain how the plurality of money maintains and how monetary systems dynamically change with its diversity kept. It is necessary to focus on the evolution of money as a socioeconomic institution backed by modern ICT.

Makoto Nishibe

nishibe@isc.senshu-u.ac.jp

1 Faculty of Economics, Senshu University, Kawasaki, Japan 
We are unknowingly captured by the stereotype that money is created and controlled solely by the state. However, the history of monopolistic national currency is not so long as we thought. It is just over 170 years since Bank Charter Act 1844 commonly known as Peel's Bank Act, had made Bank of England legitimate as the UK central bank. The idea has been very strong because it is tied up with the centrality implied in such fiscal and monetary policies executed by the state and the central bank.

We must release ourselves from such stereotype to seek a new way of adequately understanding the diversity and evolution of modern monetary systems and find a new bottom-up approach for evolutionary theory and policy with monetary diversity different from conventional top-down approaches found in micro theory without money and macro policy with a single money.

Here are three articles that tackle such challenging themes on the diversity of money using unique views and approaches from an evolutionary and institutional perspective.

J. Blanc 'Tensions in the triangle. Monetary plurality between institutional integration, competition and complementarity' proposes a new theoretical framework based on the representation of a "plurality triangle" with institutional integration, complementarity and competition according to Polanyian concepts. He can not only explain the plurality of money and its position in the monetary system, but also explore the relations of interactions of non-state currencies with state currencies in terms of institutional integration, competition and complementarity.

G. Gomez 'Why do people want currency? Institutions, habit and bricolage in an Argentine marketplace' adopts an evolutionary approach to discuss the roles of habit, institutions and bricolage in a case study on the emergence and development of a new community currency in Argentina. While the conventional theory on money emergence conceives money as the most efficient media of exchange through rational behaviors of homo economicus, she discusses evolution of an institution of money in terms of individual's civic value or social consciousness.

T. Kusago, M. Nishibe 'Community dock: a new policy approach for altering institutions' propose a new evolutionary policy approach named "community dock (CD)" to support spontaneous community development more effectively. $\mathrm{CD}$ is a synthetic method of empowerment evaluation and improvement by which research groups periodically conduct comprehensive checkups on local socioeconomy and subjective satisfactions of residents, and encourage communities to observe the outcomes of such checkups, to evaluate and solve the shared problems by themselves.

Now let me tell you that Blanc, Gomez and I are the members of Research Association on Monetary Innovation and Community and Complementary Currency Systems (RAMICS: https://ramics.org/). RAMICS plans to hold the fifth international biennial congress in Hida-Takayama, Gufu, Japan on September 11-15, 2019. Its main theme is 'Going digital? New possibilities of digital-community currency systems' and its sub-theme for practitioners' conference is 'Harmony in community currency systems between sustainability of nature, culture 
and economy and technological innovation.' The call for papers can be found on the following website (https://sites.google.com/view/ramics-2019-takayama/).

Japan Association for Evolutionary Economics (JAFEE) has decided to cosponsor the first biennial RAMICS congress in Asia. Some groups from JAFEE are going to participate in the congress and make arrangement for a special session. I hope more JAFEE members join the RAMICS 2019 Hida-Takayama. 